\title{
Management of urological dysfunction in pediatric patients with spinal dysraphism: review of the literature
}

\author{
Matthew A. Amarante, B.S., Jeffrey A. Shrensel, M.S., \\ Krystal L. Tomei, M.D., M.P.H., Peter W. Carmel, M.D., and Chirag D. Gandhi, M.D. \\ Department of Neurological Surgery, New Jersey Medical School, University of Medicine and Dentistry of \\ New Jersey, Newark, New Jersey
}

\begin{abstract}
An intact, fully functional spine is the result of a complex sequence of embryological events involving both nervous and musculoskeletal system precursors. Deviations from this highly ordered system can result in congenital abnormalities ranging from clinically insignificant cosmetic changes to CNS malformations that are incompatible with life. Closure of the neural tube, which is believed to be the embryological event gone awry in these cases, is complete by just 28 days' gestation, often before pregnancy is detected. Although progress has been made to help prevent neural tube defects in the children of those attempting to conceive, these congenital deformities unfortunately continue to affect a startling number of infants worldwide each year. Furthermore, the precise mechanisms governing closure of the neural tube and how they might be interrupted remain elusive. What is known is that there are a large number of individuals who must deal with congenital spine dysraphism and the clinical sequelae on a daily basis. Bladder and urinary dysfunction are frequently encountered, and urological care is a critical, often neglected, component in the lifelong multidisciplinary approach to treatment. Although many treatment strategies have been devised, a need remains for evidence-based interventions, analysis of quality of life, and preemptive education of both caregivers and patients as they grow older. Pediatric neurosurgeons in particular have the unique opportunity to address these issues, often in the first few days of life and throughout pre- and postoperative evaluation. With proper management instituted at birth, many patients could potentially delay or avoid the potential urological complications resulting from congenital neurogenic bladder.
\end{abstract}

(http://thejns.org/doi/abs/10.31712012.7.FOCUS12232)

KEY WORDS $\bullet \quad$ spinal dysraphism $\bullet \quad$ neural tube defect
neurogenic bladder $\bullet \quad$ urologic dysfunction

$\mathrm{N}$ EURAL tube defects are among the most common congenital abnormalities that result in significant infant morbidity and mortality, accounting for over 130,000 deaths each year (43\% of all neonatal deaths from congenital abnormalities) in regions with low income and high neonatal mortality. ${ }^{7,8}$ Anencephaly and spina bifida, the most prevalent NTDs, occur in approximately 1 in 1000 pregnancies in the US and 300,000 newborns each year worldwide. ${ }^{9}$ Myelomeningocele, a form of spina bifida, is one of the most severe CNS malformations compatible with survival. ${ }^{51}$ The overall prevalence of closed NTDs that are clinically significant is less clear, since many of these abnormalities are less obvious or hidden at birth. Recently, extensive medical and surgical care has allowed considerable numbers of infants

\footnotetext{
Abbreviations used in this paper: CIC = clean intermittent catheterization; EMG = electromyography; NBSD = neurogenic bladder sphincter dysfunction; NTD = neural tube defect; UDS = urodynamic study.
}

born with myelomeningocele to survive into adulthood, creating a significant neurosurgical population requiring continuous multidisciplinary care. Urological dysfunction is a significant deficit in these children, and neurosurgeons play a significant role in both monitoring and management of these urological concerns.

\section{Review of Spinal Dysraphisms}

The clinical spectrum of NTDs includes anencephaly, the group of anomalies considered under the term "spina bifida," encephalocele, craniorachischisis, and iniencephaly. ${ }^{35}$ Of those surviving after birth, and thus those disorders subject to clinical sequelae, the family of defects represented under the term spina bifida is by far the most prevalent. Traditionally spina bifida has been synonymous with "spinal dysraphism." Although spinal dysraphism should in theory only refer to abnormalities of primary neurulation, the term has been used to encompass all congenital spine 
disorders involving problems with differentiation and/or closure of dorsal midline structures. ${ }^{60}$

Spinal dysraphisms can be broken down into open or closed forms (Table 1). If neural elements and/or membranes are exposed to the external environment, the defect is classified as an open spinal dysraphism. The most common forms of open spinal dysraphism are myelomeningocele and myelocele, which share a common embryological pathogenesis and are associated with similar clinical implications. Closed spinal dysraphism, on the other hand, consists of spinal abnormalities covered by skin and representing a wide range of NTDs. Although many closed spinal dysraphisms go undetected or remain asymptomatic throughout the life of the patient, there are variants that may be associated with a subcutaneous mass, cord tethering, or more severe spinal cord abnormalities. ${ }^{11}$

Tethered cord is not strictly considered a malfor- mation but rather a clinical syndrome that is usually a complication of myelomeningocele repair (acquired or secondary) or the symptomatic presentation of a form of closed spinal dysraphism (congenital). The position of the conus medullaris is abnormally low (below the L-3 vertebra) and the filum terminale is often thickened. The arterioles, venules, capillaries, and nerve fibers are all subjected to stretching, distortion, and kinking that result in a spectrum of motor and sensory nerve dysfunctions ${ }^{60}$ Many cases of tethered cord syndrome are the result of retethering that occurs after the repair of a myelomeningocele (that is, in $2.8 \%-32.0 \%$ of patients usually between 5 and 9 years of age) or a lipomyelomeningocele, which is frequently associated with progressive neurological and subsequently urological deterioration.

Spinal dysraphisms are associated with a variety of structural abnormalities in addition to the primary defect

\section{TABLE 1: Classification of spinal dysraphisms*}

\begin{tabular}{|c|c|}
\hline Classification & Description \\
\hline \multicolumn{2}{|l|}{ open spinal dysraphism } \\
\hline myelomeningocele & protrusion of spinal cord segment \& meninges through a bony defect in midline of the back \\
\hline myelocele & myelomeningocele w/o expansion of underlying subarachnoid space \\
\hline hemimyelomeningocele & myelomeningocele w/ associated SCM (defect of 1 hemicord) \\
\hline hemimyelocele & myelocele w/ associated SCM (defect of 1 hemicord) \\
\hline \multicolumn{2}{|c|}{ closed spinal dysraphism w/ subcutaneous mass } \\
\hline lipomyelomeningocele & $\begin{array}{l}\text { large subcutaneous lipoma extending intraspinally; cord is tethered \& lipoma-cord interface lies } \\
\text { outside the spinal canal }\end{array}$ \\
\hline lipomyeloschisis & $\begin{array}{l}\text { large subcutaneous lipoma extending intraspinally; cord is tethered and lipoma-cord interface lies } \\
\text { w/in or at edge of spinal canal }\end{array}$ \\
\hline terminal myelocystocele & $\begin{array}{l}\text { ependyma-lined cyst (dilation of terminal ventricle) bulging through a posterior spina bifida, caus- } \\
\text { ing herniation of meninges }\end{array}$ \\
\hline lumbosacral meningocele & herniation of CSF-filled sac lined by dura \& arachnoid through a posterior spina bifida \\
\hline cervical myelocystocele & epithelial-lined cavity; only dorsal wall protrudes into meningocele \\
\hline cervical myelomeningocele & $\begin{array}{l}\text { fibroneurovascular stalk containing neurons, glia, \& peripheral nerves traveling through a narrow } \\
\text { dorsal dural opening; fans out into lining of meningeal sac; spinal cord remains in canal }\end{array}$ \\
\hline cervical meningocele & herniation of CSF-filled sac lined by dura \& arachnoid through a posterior spina bifida \\
\hline \multicolumn{2}{|c|}{ closed spinal dysraphism w/o subcutaneous mass } \\
\hline posterior spina bifida & simple failure of fusion of the posterior vertebra \\
\hline intradural \& intramedullary lipoma & encapsulated mass w/ fibrous bundles residing in spinal canal \\
\hline tight filum terminale & short, hypertrophic filum terminale resulting in tethering \& impaired ascent of conus medullaris \\
\hline abnormally long spinal cord & absence of normally tapered conus medullaris \\
\hline persistent terminal ventricle & cystic dilation of terminal ventricle; an ependyma-lined cavity in conus medullaris \\
\hline dorsal enteric fistula & $\begin{array}{l}\text { fistula connecting bowel w/ dorsal skin surface, traversing the spinal canal, spinal cord, neural } \\
\text { arch, \& subcutaneous tissue; involved segment of vertebral column \& spinal cord is split } \\
\text { around the fistula }\end{array}$ \\
\hline neurenteric cyst & $\begin{array}{l}\text { intradural cyst lined by mucin-secreting cuboidal or columnar epithelium that resembles gastroin- } \\
\text { testinal tract }\end{array}$ \\
\hline split cord malformation & variations of splitting of spinal cord into 2 hemicords \\
\hline dermal sinus & epithelium-lined fistula extending into the CNS; point of termination varies \\
\hline caudal regression syndrome & $\begin{array}{l}\text { family of anomalies representing total or partial agenesis of the spinal column, imperforate anus, } \\
\text { genital anomalies, bilat renal dysplasia/aplasia, \& pulmonary hypoplasia }\end{array}$ \\
\hline segmental spinal dysgenesis & $\begin{array}{l}\text { segmental agenesis/dysgenesis of lumbar/thoracolumbar spine, segmental abnormality of spinal } \\
\text { cord \& nerve roots, congenital paraplegia or paraparesis, and congenital lower-limb deformities }\end{array}$ \\
\hline
\end{tabular}

* Based in part on data from Tortori-Donati et al: Neuroradiology 42:471-491, 2000. Abbreviation: SCM = split cord malformation. 


\section{Urological dysfunction in spinal dysraphism}

of neurulation. The mesoderm that forms the vertebrae is also the precursor for the mesonephros, an embryological structure that represents an important stage in the development of the mature genitourinary system. This association explains the frequency of coexisting anomalies of the urinary tract and congenital spine dysraphisms. ${ }^{33}$ In a study of infants with urogenital anomalies, it was noted that they had a higher prevalence of closed spinal dysraphism (23 per 1000 vs 1 per 1000). ${ }^{36}$ Infants in the abnormal group exhibited a consistently lower conus medullaris and thicker filum terminale when compared with healthy infants without anomalies.

\section{Diagnosis}

Urological dysfunction in children may be present from birth in individuals with open NTDs, or it may present later in life in individuals with closed NTDs, such as lipomyelomeningocele, or in those with a secondary tethered cord. Establishment of a diagnosis generally relies on the children and parents monitoring urinary function to assess for changes such as incontinence, changes in urinary frequency, urinary tract infections, or other alterations in the patient's baseline urological function. Of importance for all children with spinal dysraphisms is the monitoring of urological function throughout their clinical course, as early detection of worsening urological function combined with timely surgical intervention is important for the prevention of progressive deterioration. A long-term follow-up study of 25 newborns after myelomeningocele and meningocele repair demonstrated the importance of regular follow-up of urinary function, as those individuals younger than 6 years were at higher risk of secondary tethered cord and subsequent urological deterioration. ${ }^{57}$ In an evaluation of 25 children with spina bifida, Kumar et al. ${ }^{38}$ demonstrated abnormal baseline urodynamics in $90 \%$ of children with open defects and $66.6 \%$ of children with closed defects. Because these children may have a baseline degree of urological dysfunction or subclinical urological dysfunction, the neurosurgeon must rely on colleagues in urology, as well as urodynamic function studies, to assess for changes in urological function. Further preoperative evaluation of these children will be discussed.

\section{Innervation of the Genitourinary System}

Central control of bladder function begins in the locus coeruleus of the pons, which is responsible for a reflex pathway that synchronizes bladder contraction with internal urethral sphincter relaxation during voiding (Fig. 1). ${ }^{40}$ With appropriate training, cortical signals can voluntarily suppress this reflex. Infants who have not yet acquired this control have an uninhibited pontine reflex. Thus, the detrusor muscle contracts and the internal sphincter relaxes when a critical urine capacity is reached. ${ }^{65}$ Parasympathetic fibers are the primary innervation of the urinary bladder. Presynaptic fibers arise from neurons in the S2-4 cord segments and travel via pelvic splanchnic nerves and the inferior hypogastric and vesical plexuses to the bladder. They form synapses with postsynaptic neurons that

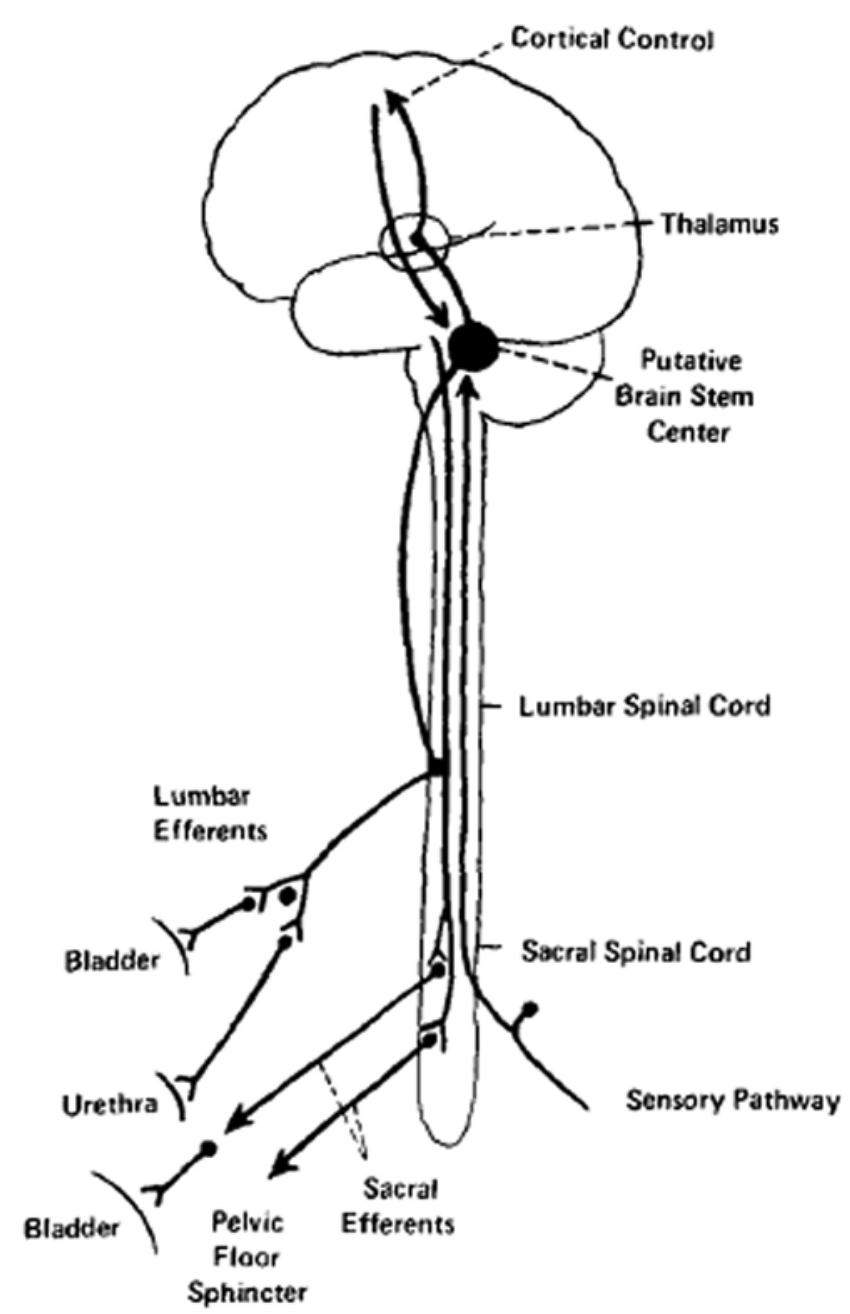

Fig. 1. Diagram of the neural input to lower urinary tract function. The brainstem response is inhibitory to detrusor muscle via the pudendal nerve. Thoracolumbar autonomic innervation is responsible for relaxation of the detrusor and contraction of urethral smooth muscle. Reproduced from McGuire: J Neurosurg 65:278-285, 1986.

are found on or near the bladder wall. Parasympathetic fibers provide motor innervation to the detrusor muscle and inhibit the internal urethral sphincter. Sympathetic fibers arise from the T11-L3 cord segments, travel via lumbar splanchnic nerves, and synapse on the hypogastric system of plexuses. ${ }^{46}$ Sympathetic nerves have little role in bladder motor activity, but they do appear to heavily innervate the neck and trigone of the bladder. Sympathetic stimulation allows for bladder neck closure, which is crucial for bladder filling. Somatic fibers to the external urethral sphincter arise from motor neurons in the S2-4 cord segments and travel to the bladder via the pudendal nerve. Although the external sphincter can be contracted voluntarily, it relaxes reflexively when micturition is initiated via cortical signals and the internal sphincter opens. ${ }^{25}$

\section{Urological Sequelae}

Most closed spinal dysraphisms or tethered cord syndromes are diagnosed following manifestation of neuro- 
logical symptoms or are discovered incidentally during workup for unrelated problems. These neurological sequelae can include muscular deformity, bowel and bladder incontinence, sexual dysfunction, lower-extremity sensory loss, and paraplegia in severe cases. ${ }^{33}$ Patients with closed spinal dysraphisms may present with signs and symptoms much more insidious in nature, with the exception of the cutaneous markers that may be associated with $43 \%-95 \%$ of cases, so urological symptoms in these patients may go unnoticed until later in life..$^{2,5,21,26,31,44,52}$ New-onset urinary incontinence, changes in voiding patterns, or recurrent urinary tract infections are indications for additional workup. Clinically significant symptoms are usually the result of pathology or abnormalities that cause spinal cord tethering. ${ }^{55}$

The urological sequelae of myelomeningocele, the most common open spinal dysraphism, have been well studied. Urinary symptoms were initially thought to be the result of paresis of the detrusor muscle and/or sphincter muscles. It was not until the development of pediatric urodynamics in the late 1970s and early 1980s that physicians realized that detrusor-sphincter dyssynergia, which creates a functional bladder outlet obstruction, may also be the primary issue. In fact, children with myelomeningocele may show any of 4 unique combinations of detrusor muscle and urethral sphincter activity (detrusor overactivity with sphincter overactivity; detrusor inactivity with sphincter overactivity; detrusor overactivity with sphincter inactivity; and detrusor inactivity with sphincter inactivity). The type of detrusor-sphincter dyssynergia tends to remain consistent during follow-up because it represents the manifestation of the primary neurological lesion. The clinical manifestations include incontinence that results from urethral sphincter inactivity and obstruction, which results from urethral sphincter overactivity. ${ }^{61}$ Regardless of the underlying mechanism, the consequences of untreated urological sequelae are severe. Renal failure within the 1st year of life is responsible for up to $20 \%$ of deaths. Renal damage begins as early as 6 months of age, and up to $100 \%$ of children with untreated dyssynergia have renal scarring..$^{16}$ Complications of poor urological management occur in a progressive fashion. Urinary stasis, combined with vesicoureteral reflux, leads to an increased incidence of infection of the urinary tract, bladder, and kidney, as well as an increased risk of urinary tract calculi. Elevated bladder pressure can lead to hydronephrosis, renal deterioration, renal failure, and ultimately death. Furthermore, the incidence of bladder cancer is significantly elevated, sexual dysfunction is common, and there is often physical damage due to longterm catheterization. ${ }^{24} \mathrm{With}$ proper treatment and patient compliance, physicians can now ensure preservation of renal function provided that interventions begin immediately after birth. Quality of life improvements continue to be explored to address the social implications of management strategies.

\section{Urodynamic Testing}

Urodynamic studies provide a reliable way to evaluate the function of the lower urinary tract and can be adapted specifically for use in children. Significant controversy exists about the use of invasive urodynamic testing in children with nonneurogenic voiding disorders because these children may often be evaluated with noninvasive UDSs and managed expectantly with behavioral and pharmacological therapy. ${ }^{18}$ However, identification or confirmation of neurogenic bladder is an excellent use of UDSs, providing more specific and accurate information than imaging, neurological examination, and symptomatology alone. ${ }^{18}$ Noninvasive UDSs consist of uroflowmetry and postvoid residual measurement. Uroflowmetry can be used in isolation, simply measuring the child's ability to empty the bladder, or as part of more comprehensive studies. In children, the flow pattern is more useful than the rate of flow, as it can provide information about detrusor function, amount of outlet resistance, and degree of external urethral sphincter activity. Postvoid residual measurements may be performed using ultrasonography or specialized bladder scanners, and abnormal values indicate a need for repeated measurements or further workup. Jansson et al. ${ }^{29}$ found that the median postvoid residual in 6-month old infants was $5 \mathrm{ml}(\mathrm{r}=0-22)$, decreasing to a median of $0 \mathrm{ml}$ at age $3(\mathrm{r}=0-18)$.

If noninvasive UDSs show abnormal bladder function, either through postvoid residual measurement or bladder enlargement, invasive studies are warranted, including cystometrography, in which rectal and urethral catheters measure intraabdominal and intravesical pressures. Perineal EMG patches may be added to assess external urethral sphincter activity. To perform the test, the bladder is filled using a multilumen catheter until the child feels a strong urge to urinate, becomes uncomfortable, urination occurs, detrusor pressure exceeds $40 \mathrm{~mm}$ $\mathrm{H}_{2} \mathrm{O}$, greater than $150 \%$ of expected capacity has been infused, or the leakage rate exceeds the infusion rate. Fluoroscopy can be used during filling-phase studies to visualize the shape and contours of the bladder while full or voiding, as well as intrinsic sphincter deficiency in patients with neurogenic bladder disease and dynamic dysfunction. Evaluation of the storage function of the bladder is typically described subjectively in terms of bladder sensation (as well as objective values such as compliance, activity, and capacity) and, therefore, is only of use in patients able to describe what they are feeling. In younger patients, however, signs such as toe curling or abdominal tensing may be indicative of a full bladder, signifying incipient micturation. ${ }^{48}$ Bladder capacity and compliance are then determined, although there are no standardized reference values available for compliance in children or adults; this is further complicated in that compliance varies according to capacity at the time of measurement and in that capacity does not change linearly with age. ${ }^{18}$ Finally, in children capable of spontaneous voiding, voiding-phase studies measure voiding pressure and flow rate, with attention paid to whether voiding pressure has been maintained throughout the duration of bladder contraction until completely empty, as well as any external urethral sphincter activity, monitored through EMG. As in filling studies, concurrent imaging of the bladder improves diagnostic interpretation and characterization of any pathology. ${ }^{22}$ 


\section{Current Strategies for Management of Urological Dysfunction}

Prompt detection of children with high-risk urological dysfunction and early intervention is key in protecting against hydronephrosis, preserving renal function and preventing the development of a poorly compliant bladder ${ }^{16}$ Neurogenic bladder sphincter dysfunction can cause these problems long before continence becomes an issue. There are several types of NBSD seen clinically, consisting of the previously mentioned combinations of detrusor over- and underactivity and sphincter over- and underactivity. Management is determined by the consequences of the particular combination. Of all four types, only the combination of sphincter underactivity and detrusor underactivity is inherently "safe" in that, untreated, it will not lead to urinary tract damage, although it does result in incontinence and increased rates of urinary tract infection. ${ }^{62}$

All of the other forms of NBSD include CIC to empty the bladder. In the case of sphincter overactivity with detrusor underactivity, it is the only management needed to control urinary tract damage and leakage. With proper parental/caregiver education, and with the practice of proper basic technique, including clean and atraumatic catheter application, the specific techniques and materials used are unimportant with regard to efficacy. ${ }^{62}$ It should be noted, however, that Credé voiding is not recommended for noncatheterized patients because it can result in compression of the external urethral sphincter, causing high pressure voiding or reflux in some patients, which is detrimental to the upper urinary tract. ${ }^{14}$ Beginning CIC early in infancy conveys several advantages over expectant treatment, including easier caregiver and patient adaptation to the routine and less need for augmentation cystoplasty ${ }^{20,30,66}$ As the children age and develop manual dexterity, they may be transitioned to clean intermittent self-catheterization. ${ }^{62}$

In addition to CIC, pharmacological treatment in the form of the anticholinergic oxybutynin is used to treat both forms of NBSD involving detrusor overactivity, long-term studies having demonstrated safety in children and infants and efficacy in lowering filling pressure, increasing bladder capacity, and preventing renal damage. ${ }^{62}$ Pharmacological treatment can be administered orally or as an intravesical preparation in children with significant side effects or a poor response to the oral form. ${ }^{12}$ The combined therapy of CIC and oxybutynin is successful in treating $90 \%$ of patients with NBSD, but for those patients in whom this therapy is unsuccessful, other drugs such as propiverine or tolterodine are available, but there is relatively little published information on efficacy in children. ${ }^{62}$ Recent work has indicated that injection of botulinum A toxin may be a viable treatment in children unresponsive to CIC and oxybutynin. ${ }^{39}$

After a treatment regimen is chosen, follow-up to assess for efficacy is needed. Assessment can include ultrasound, UDS, cystography, urinalysis, or other tests. The frequency of visits can be tapered from 3 per year in children up to age 3,2 per year in school-age children, and annually in adults. ${ }^{62}$
Several urological procedures exist for the purpose of increasing bladder capacity and for urinary diversion. These procedures include ureterostomy, vesicostomy, ileal conduit, and ileovesicostomy. Although these procedures are outside the scope of the present review, they are well described in the urology literature. ${ }^{23,63,64}$

\section{Neurosurgical Intervention}

The particular role of the neurosurgeon in the management of urological dysfunction revolves around the preoperative evaluation of children with urological complaints, intraoperative techniques to release a tethered cord and limit neural injury during surgery, and postoperative monitoring for further deterioration. Newer techniques are emerging to reinnervate the bladder. A strategy for management during each of these stages follows.

Preoperative evaluation of any child with a primary urological complaint of possible neurogenic origin should include formal urological assessment, which may include a bladder ultrasound or invasive urodynamic testing as previously described. Additionally, imaging tests such as an MRI may reveal evidence of a closed defect or tethered cord as the likely cause. As many children may be referred to a neurosurgeon after advanced imaging studies have already been completed, the referral to a urologist and correlation of symptoms with results of a urological assessment should follow. This becomes especially important in children with secondary tethered cord in whom there are radiographic concerns of tethering even in the absence of clear symptoms. ${ }^{4,43}$ Often in these patients the presence of symptoms rather than radiographic findings should take precedence. Suspicion of a symptomatic tethered cord should be raised when there changes in a child's baseline urinary pattern because these changes may represent secondary tethered cord or development of syringomyelia.

Additional testing such as neurophysiological evaluation may be of assistance in confirming neurological dysfunction. Torre et al. ${ }^{59}$ undertook electrophysiological testing in 28 children with spinal dysraphisms and found that a combination of electrophysiological tests yielded good predictive results. Combined results from EMG and perineal evoked potentials monitoring predicted vesicosphincter dyssynergia with $100 \%$ sensitivity and bladder dysmotility with $86 \%$ sensitivity. Perineal evoked potentials alone detected urodynamic dysfunction with $90 \%$ specificity, and EMG combined with perineal evoked potentials confirmed urological dysfunction with $79 \%$ sensitivity, yet a negative predictive value of $90 \%$.

Surgical intervention can be divided into 2 categories-primary surgery and secondary release of tethered cord-with an overarching surgical goal of releasing the tethered cord to prevent further deterioration in urological function. For open NTDs, the surgical technique involves releasing the edges of the neural placode, reapproximating the pial edges of the placode to reform the neural tube, and creating a CSF-filled space within the dural closure. Additionally, any existing filum may be transected at the time of initial surgery. For closed NTDs such as lipomyelomeningoceles, the area of tether, 
namely where the lipoma pierces the lumbosacral fascia, should be identified and released, and attempts to debulk the lipoma and reapproximate the placode should be made where it is possible. Additionally, one should create a large CSF space around the spinal cord during the dural repair to reduce the risk of retethering. Children who have undergone a primary surgery previously mentioned are at risk for a secondary tethered cord due to scarring in the postoperative site. For these patients, the goal is to release the tether by lysing the arachnoid adhesions and scar tissue that serves as the location of tether and causes urological deterioration.

Recently, prenatal intrauterine repair has been receiving increased attention. The Management of Myelomeningocele Study (MOMS) was conducted to specifically address whether this strategy had improved outcomes compared with traditional postnatal surgery, but urological function in these patients was not assessed. ${ }^{3}$ Other studies with long-term outcomes of intrauterine myelomeningocele repair have shown a range of urological outcomes. A long-term follow-up study of 28 patients who underwent fetal myelomeningocele closure demonstrated a range of urological dysfunctions in this subset (decreased bladder capacity, detrusor overactivity, and increased detrusor pressure) and no significant difference compared with individuals who underwent traditional postnatal repair..$^{15}$ However, a limited number of studies have also shown an improvement in urodynamic outcome, but there are minimal data to substantiate this. ${ }^{13}$ Given the evolving expertise in fetal myelomeningocele closure, further investigation into the urological outcomes after intrauterine repair should be forthcoming.

Neurophysiological monitoring may be used to assist the surgeon with intraoperative planning by alerting the surgeon to changes in monitoring parameters during surgery to reduce the risk of neurological injury and iatrogenic worsening of urological function. ${ }^{53}$ Total intravenous anesthesia and minimal use of muscle relaxants facilitate the use of somatosensory evoked potentials, motor evoked potentials, and EMG, both free run and stimulated. ${ }^{6,28}$ Monitoring frequently includes lower-extremity muscle groups and sensory distributions as well as the anal sphincter. The innervation of the anal sphincter by the lower sacral nerves (S2-5) is a good proxy for assessing bladder function integrity because of similar innervation (Fig. 2). ${ }^{28}$ It is possible to monitor the external urethral sphincter by way of a special ring electrode on a Foley catheter. ${ }^{34}$ However, in a pediatric population, urethral size may be prohibitive to this monitoring strategy. The combination of free-run and stimulated EMG allows for continuous EMG monitoring and assessment of structures during dissection, which may be beneficial when encountering dysmorphic neural elements. ${ }^{34,37}$

The risk of a retethering in patients with spinal dysraphisms may be as low as $3 \%$ or as high as $40 \%$, occurring most frequently in patients who underwent primary repair of myelomeningocele and resection of lipomyelomeningocele. . $^{17,27,32,47,54,56}$ Given this elevated risk for future neurological decline, postoperative monitoring of urological function is critical. This includes monitoring of urological function by patients and their family, most importantly noting changes in urological function, especially in the population in which a baseline degree of function requires catheterization. Symptoms may include episodes of incontinence or changes in urinary habits. These patients should be followed up by a urologist for urodynamic evaluation, especially during periods of growth when a patient's cord is as greatest risk of injury secondary to a tether. Similar to preoperative assessment, any concern about a change in urinary function should prompt urgent evaluation, either urodynamic testing or neurophysiological testing.

\section{Neurosurgical Outcomes}

The initial goals for neurosurgical repair in open spinal dysraphism include elimination of CSF leakage, prevention of infection, preservation of neural function, and prevention of secondary tethering postoperatively. Once definitive repair is completed, the focus generally shifts to lifestyle improvements. Bowel and bladder dysfunction remains a primary morbidity concern as bladder dysfunction predisposes this group to the risks of recurrent urinary tract infections, pyelonephritis, hydronephrosis, and, in severe cases, renal failure. Given that the primary repair of myelomeningocele often occurs within the first few days of life, when no baseline urological function is known, the outcomes of interest generally arise after a patient presents with worsening urological function due to a tethered cord.

Initial surgical intervention for spina bifida has been shown to result in some improvement in urological function. In the previously mentioned study by Kumar et al., ${ }^{38}$ $42.8 \%$ of patients with open defects and $46.2 \%$ of those with closed defects experienced improvement in urological function after an initial surgical intervention. Wu and colleagues ${ }^{67}$ reviewed data obtained in 43 patients who underwent early surgery for lipomyelomeningocele prior to manifestation of urological dysfunction; they found that $84 \%$ of the patients maintained stable function. Macejko et al. ${ }^{41}$ however, reviewed the cases of 79 patients who underwent primary release of a tethered cord inclusive of closed defects and demonstrated that those with lipomyelomeningocele were at risk for the poorest urological outcomes after surgery. In contrast, evaluation of 36 patients with occult tethered spinal cord who underwent sectioning of the filum terminale demonstrated improvement in urinary symptoms in $72 \%$ and resolution of incontinence in $42 \% .45$

Surgical intervention for tethered cord manifesting with worsening urological function also demonstrates a wide range of improvement in urological function after surgery. Tarcan and associates ${ }^{58}$ reported on 56 patients with secondary tethering after repair of myelomeningocele and evaluated outcomes after a detethering procedure. They tiered the outcomes according to the initial grade of urinary tract dilation. Individuals with Grade 1-2 dilation had an improvement in grade in $40 \%$ of the cases and complete resolution of the dilation in $33.3 \%$. Those with Grade 3-4 dilation had an improvement in $50 \%$ of the cases and resolution in none. However, more profound improvement was noted in the degree of vesico- 


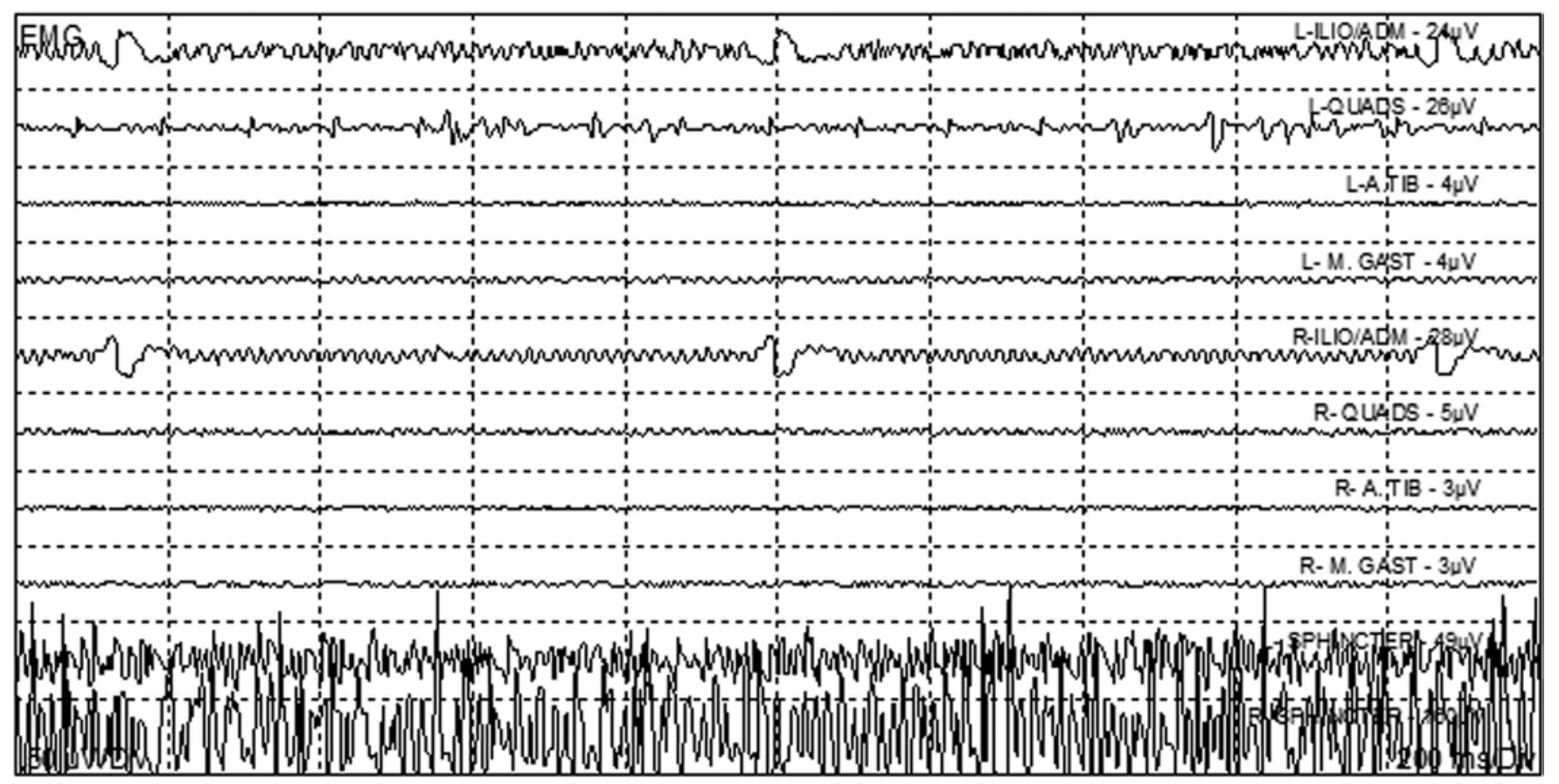

FIG. 2. Intraoperative EMG tracing obtained during a tethered cord release demonstrating train activity of the anal sphincter that can be noted with manipulation of the lumbosacral nerve roots. From top to bottom: left iliopsoas/adductor, left quadriceps, left anterior tibialis, left gastrocnemius, right iliopsoas/adductor, right quadriceps, right anterior tibialis, right gastrocnemius, left anal sphincter, right anal sphincter.

ureteral reflux, which resolved in $62.5 \%$ of patients with Grade 1-3 reflux and improved in $37.5 \%$. Patients with Grade 4-5 reflux demonstrated resolution in $33.3 \%$ and improvement in $40 \%$. These results were most significant in children treated before the age of 7 years. In a review of 20 patients who underwent surgery for various manifestations of tethered cord, Abrahamsson et al. ${ }^{1}$ demonstrated that in all patients with deterioration in urodynamic function prior to untethering function improved after surgery, and in $90 \%$ with stable urological function prior to surgery function, remained stable. Dushi and coworkers ${ }^{19}$ introduced a urodynamic score as a means of assessing outcome and demonstrated that the postoperative score improved in 55\% of patients who presented with urological symptoms and in $86 \%$ of those who did not present with urological symptoms. As previously mentioned, these positive outcomes may be subclinical. Palmer et al. ${ }^{50}$ reviewed the cases of 20 children who initially presented with worsening scoliosis or lower-extremity function and no discernible change in their urological function; they found that even within this group, $75 \%$ of the patients had improved urodynamic function after tethered cord release. These results are not limited to the first untethering procedure, as Maher et al. ${ }^{42}$ demonstrated improvement in urological function in $71 \%$ of patients who underwent multiple repeat untethering operations.

\section{Conclusions}

Spinal dysraphism and other forms of NTDs continue to be significant sources of morbidity and mortality worldwide. Until the 1950 s, the probability that an infant with a severe abnormality, such as myelomeningocele, would survive to adulthood was low. Therapeutic advancements and improvement in neurosurgical technique have drastically changed the nature of these congenital malformations. In fact, adults with myelomeningocele now account for greater health care expenditures and more hospital admissions than children with this condition. ${ }^{49}$ Thus, the focus of treatment is rapidly shifting toward early recognition and surgical intervention, postoperative monitoring and management, and improvements in patient quality of life.

Perhaps the most critical consideration is the lifelong bladder and urinary dysfunction encountered by these patients. A wide range of clinical pathology can lead to damage of nerves of the genitourinary system, often as a result of spinal cord tethering. Without treatment, the urological sequelae are debilitating and often fatal. For the neurosurgeon involved in the care of such patients, early and frequent urodynamic testing, combined with a multidisciplinary approach involving urologists to guide management, is crucial to improve outcomes. Early detection and surgery for worsening urological dysfunction remains the mainstay for treatment of primary and secondary tethered cord to minimize the long-term effects of irreversible urological dysfunction. Although recent trials have shown promising results with prenatal neurosurgical intervention, it remains to be seen whether these techniques result in consistent favorable urological outcomes. Increasing awareness among neurosurgeons who encounter spinal dysraphisms is one of the first steps in lifelong management that can both drastically improve quality of life and lower future health expenditures. 


\section{Disclosure}

The authors report no conflict of interest concerning the materials or methods used in this study or the findings specified in this paper.

Author contributions to the study and manuscript preparation include the following. Conception and design: Tomei. Acquisition of data: Amarante, Shrensel. Drafting the article: Amarante, Shrensel, Tomei. Critically revising the article: all authors. Reviewed submitted version of manuscript: all authors. Study supervision: Gandhi, Tomei, Carmel.

\section{Acknowledgments}

The authors thank Joseph Danto, Ph.D., and Betzaida Vazquez, CNIM of Physiologic Assessment Services, Inc., for their contribution of EMG monitoring data. The authors also thank Cesar Mora, M.D, Division of Urology, New Jersey Medical School, University of Medicine and Dentistry of New Jersey, for his expert review.

\section{References}

1. Abrahamsson K, Olsson I, Sillén U: Urodynamic findings in children with myelomeningocele after untethering of the spinal cord. J Urol 177:331-334, 2007

2. Ackerman LL, Menezes AH: Spinal congenital dermal sinuses: a 30-year experience. Pediatrics 112:641-647, 2003

3. Adzick NS, Thom EA, Spong CY, Brock JW III, Burrows PK, Johnson MP, et al: A randomized trial of prenatal versus postnatal repair of myelomeningocele. N Engl J Med 364:9931004, 2011

4. Arai H, Sato K, Okuda O, Miyajima M, Hishii M, Nakanishi $\mathrm{H}$, et al: Surgical experience of 120 patients with lumbosacral lipomas. Acta Neurochir (Wien) 143:857-864, 2001

5. Assaad A, Mansy A, Kotb M, Hafez M: Spinal dysraphism: experience with 250 cases operated upon. Childs Nerv Syst 5: 324-329, 1989

6. Beyazova M, Zinnuroglu M, Emmez H, Kaya K, Ozkose HZ, Baykaner MK, et al: Intraoperative neurophysiological monitoring during surgery for tethered cord syndrome. Turk Neurosurg 20:480-484, 2010

7. Birnbacher R, Messerschmidt AM, Pollak AP: Diagnosis and prevention of neural tube defects. Curr Opin Urol 12:461464, 2002

8. Blencowe H, Cousens S, Modell B, Lawn J: Folic acid to reduce neonatal mortality from neural tube disorders. Int J Epidemiol 39 (Suppl 1):i110-i121, 2010

9. Botto LD, Moore CA, Khoury MJ, Erickson JD: Neural-tube defects. N Engl J Med 341:1509-1519, 1999

10. Bowman RM, McLone DG, Grant JA, Tomita T, Ito JA: Spina bifida outcome: a 25-year prospective. Pediatr Neurosurg 34:114-120, 2001

11. Bulas D: Fetal evaluation of spine dysraphism. Pediatr Radiol 40:1029-1037, 2010

12. Buyse G, Verpoorten C, Vereecken R, Casaer P: Intravesical application of a stable oxybutynin solution improves therapeutic compliance and acceptance in children with neurogenic bladder dysfunction. J Urol 160:1084-1087, 1998

13. Carr MC: Fetal myelomeningocele repair: urologic aspects. Curr Opin Urol 17:257-262, 2007

14. Churchill BM, Abramson RP, Wahl EF: Dysfunction of the lower urinary and distal gastrointestinal tracts in pediatric patients with known spinal cord problems. Pediatr Clin North Am 48:1587-1630, 2001

15. Clayton DB, Tanaka ST, Trusler L, Thomas JC, Pope JC IV, Adams MC, et al: Long-term urological impact of fetal myelomeningocele closure. J Urol 186 (4 Suppl):1581-1585, 2011

16. de Jong TP, Chrzan R, Klijn AJ, Dik P: Treatment of the neurogenic bladder in spina bifida. Pediatr Nephrol 23:889-896, 2008
17. Dias MS: Neurosurgical management of myelomeningocele (spina bifida). Pediatr Rev 26:50-60, 2005

18. Drzewiecki BA, Bauer SB: Urodynamic testing in children: indications, technique, interpretation and significance. J Urol 186:1190-1197, 2011

19. Dushi G, Frey P, Ramseyer P, Vernet O, Meyrat BJ: Urodynamic score in children with lipomyelomeningocele: a prospective study. J Urol 186:655-659, 2011

20. Edelstein RA, Bauer SB, Kelly MD, Darbey MM, Peters CA, Atala A, et al: The long-term urological response of neonates with myelodysplasia treated proactively with intermittent catheterization and anticholinergic therapy. J Urol 154:15001504,1995

21. Gibson PJ, Britton J, Hall DM, Hill CR: Lumbosacral skin markers and identification of occult spinal dysraphism in neonates. Acta Paediatr 84:208-209, 1995

22. Glazier DB, Murphy DP, Fleisher MH, Cummings KB, Barone JG: Evaluation of the utility of video-urodynamics in children with urinary tract infection and voiding dysfunction. $\mathbf{B r}$ J Urol 80:806-808, 1997

23. González R, Schimke CM: Strategies in urological reconstruction in myelomeningocele. Curr Opin Urol 12:485-490, 2002

24. Gormley EA: Urologic complications of the neurogenic bladder. Urol Clin North Am 37:601-607, 2010

25. Greenberg MS: Handbook of Neurosurgery, ed 7. New York: Thieme Medical Publishers, 2010

26. Guggisberg D, Hadj-Rabia S, Viney C, Bodemer C, Brunelle F, Zerah M, et al: Skin markers of occult spinal dysraphism in children: a review of 54 cases. Arch Dermatol 140:1109-1115, 2004

27. Herman JM, McLone DG, Storrs BB, Dauser RC: Analysis of 153 patients with myelomeningocele or spinal lipoma reoperated upon for a tethered cord. Presentation, management and outcome. Pediatr Neurosurg 19:243-249, 1993

28. Hoving EW, Haitsma E, Oude Ophuis CM, Journée HL: The value of intraoperative neurophysiological monitoring in tethered cord surgery. Childs Nerv Syst 27:1445-1452, 2011

29. Jansson UB, Hanson M, Sillén U, Hellström AL: Voiding pattern and acquisition of bladder control from birth to age 6 years-a longitudinal study. J Urol 174:289-293, 2005

30. Kaefer M, Pabby A, Kelly M, Darbey M, Bauer SB: Improved bladder function after prophylactic treatment of the high risk neurogenic bladder in newborns with myelomeningocele. $\mathbf{J}$ Urol 162:1068-1071, 1999

31. Kanev PM, Lemire RJ, Loeser JD, Berger MS: Management and long-term follow-up review of children with lipomyelomeningocele, 1952-1987. J Neurosurg 73:48-52, 1990

32. Kang JK, Lee KS, Jeun SS, Lee IW, Kim MC: Role of surgery for maintaining urological function and prevention of retethering in the treatment of lipomeningomyelocele: experience recorded in 75 lipomeningomyelocele patients. Childs Nerv Syst 19:23-29, 2003

33. Kaplan KM, Spivak JM, Bendo JA: Embryology of the spine and associated congenital abnormalities. Spine J 5:564-576, 2005

34. Khealani B, Husain AM: Neurophysiologic intraoperative monitoring during surgery for tethered cord syndrome. J Clin Neurophysiol 26:76-81, 2009

35. Kondo A, Kamihira O, Ozawa H: Neural tube defects: prevalence, etiology and prevention. Int J Urol 16:49-57, 2009

36. Koo BN, Hong JY, Song HT, Kim JM, Kil HK: Ultrasonography reveals a high prevalence of lower spinal dysraphism in children with urogenital anomalies. Acta Anaesthesiol Scand 56:624-628, 2012

37. Kothbauer KF, Novak K: Intraoperative monitoring for tethered cord surgery: an update. Neurosurg Focus 16(2):E8, 2004

38. Kumar R, Singhal N, Gupta M, Kapoor R, Mahapatra AK: Evaluation of clinico-urodynamic outcome of bladder dysfunction after surgery in children with spinal dysraphism-a prospective study. Acta Neurochir (Wien) 150:129-137, 2008 
39. Kuo YC, Kuo HC: Botulinum toxin injection for lower urinary tract dysfunction. Int J Urol [epub ahead of print], 2012

40. MacDiarmid S: The patient presenting with neurological disease affecting the urinary tract, in Norman RW, Currow D (eds): Supportive Care for the Urology Patient. New York: Oxford University Press, 2005, pp 163-179

41. Macejko AM, Cheng EY, Yerkes EB, Meyer T, Bowman RM, Kaplan WE: Clinical urological outcomes following primary tethered cord release in children younger than 3 years. J Urol 178:1738-1743, 2007

42. Maher CO, Bauer SB, Goumnerova L, Proctor MR, Madsen JR, Scott RM: Urological outcome following multiple repeat spinal cord untethering operations. Clinical article. J Neurosurg Pediatr 4:275-279, 2009

43. Maher CO, Goumnerova L, Madsen JR, Proctor M, Scott RM: Outcome following multiple repeated spinal cord untethering operations. J Neurosurg 106 (6 Suppl):434-438, 2007

44. McAtee-Smith J, Hebert AA, Rapini RP, Goldberg NS: Skin lesions of the spinal axis and spinal dysraphism. Fifteen cases and a review of the literature. Arch Pediatr Adolesc Med 148:740-748, 1994

45. Metcalfe PD, Luerssen TG, King SJ, Kaefer M, Meldrum KK, Cain MP, et al: Treatment of the occult tethered spinal cord for neuropathic bladder: results of sectioning the filum terminale. J Urol 176:1826-1830, 2006

46. Moore KL, Dalley AF, Agur AMR: Clinically Oriented Anatomy, ed 6. Philadelphia: Lippincott Williams \& Wilkins, 2009

47. Morimoto K, Takemoto O, Wakayama A: Spinal lipomas in children-surgical management and long-term follow-up. Pediatr Neurosurg 41:84-87, 2005

48. Nijman RJ: Diagnosis and management of urinary incontinence and functional fecal incontinence (encopresis) in children. Gastroenterol Clin North Am 37:731-748, 2008

49. Ouyang L, Grosse SD, Armour BS, Waitzman NJ: Health care expenditures of children and adults with spina bifida in a privately insured U.S. population. Birth Defects Res A Clin Mol Teratol 79:552-558, 2007

50. Palmer LS, Richards I, Kaplan WE: Subclinical changes in bladder function in children presenting with nonurological symptoms of the tethered cord syndrome. J Urol 159:231-234, 1998

51. Piatt JH Jr: Treatment of myelomeningocele: a review of outcomes and continuing neurosurgical considerations among adults. A review. J Neurosurg Pediatr 6:515-525, 2010

52. Pierre-Kahn A, Lacombe J, Pichon J, Giudicelli Y, Renier D, Sainte-Rose C, et al: Intraspinal lipomas with spina bifida. Prognosis and treatment in 73 cases. J Neurosurg 65:756-761, 1986

53. Pouratian N, Elias WJ, Jane JA Jr, Phillips LH II, Jane JA Sr: Electrophysiologically guided untethering of secondary tethered spinal cord syndrome. Neurosurg Focus 29(1):E3, 2010

54. Shurtleff DB, Duguay S, Duguay G, Moskowitz D, Weinberg- er E, Roberts T, et al: Epidemiology of tethered cord with meningomyelocele. Eur J Pediatr Surg 7 (Suppl 1):7-11, 1997

55. Sutherland RS, Mevorach RA, Baskin LS, Kogan BA: Spinal dysraphism in children: an overview and an approach to prevent complications. Urology 46:294-304, 1995

56. Tamaki N, Shirataki K, Kojima N, Shouse Y, Matsumoto S: Tethered cord syndrome of delayed onset following repair of myelomeningocele. J Neurosurg 69:393-398, 1988

57. Tarcan T, Bauer S, Olmedo E, Khoshbin S, Kelly M, Darbey M: Long-term followup of newborns with myelodysplasia and normal urodynamic findings: is followup necessary? J Urol 165:564-567, 2001

58. Tarcan T, Onol FF, Ilker Y, Simsek F, Ozek M: Does surgical release of secondary spinal cord tethering improve the prognosis of neurogenic bladder in children with myelomeningocele? J Urol 176:1601-1606, 2006 (Erratum in J Urol 176 (6 Pt 1):2749, 2006)

59. Torre M, Planche D, Louis-Borrione C, Sabiani F, Lena G, Guys JM: Value of electrophysiological assessment after surgical treatment of spinal dysraphism. J Urol 168:1759-1763, 2002

60. Tortori-Donati P, Rossi A, Cama A: Spinal dysraphism: a review of neuroradiological features with embryological correlations and proposal for a new classification. Neuroradiology 42:471-491, 2000

61. van Gool JD, Dik P, de Jong TP: Bladder-sphincter dysfunction in myelomeningocele. Eur J Pediatr 160:414-420, 2001

62. Verpoorten C, Buyse GM: The neurogenic bladder: medical treatment. Pediatr Nephrol 23:717-725, 2008

63. Westney OL: The neurogenic bladder and incontinent urinary diversion. Urol Clin North Am 37:581-592, 2010

64. Wiener JS, Antonelli J, Shea AM, Curtis LH, Schulman KA, Krupski TL, et al: Bladder augmentation versus urinary diversion in patients with spina bifida in the United States. J Urol 186:161-165, 2011

65. Winn HR (ed): Youmans Neurological Surgery, ed 6. Philadelphia: Saunders, 2011

66. Wu HY, Baskin LS, Kogan BA: Neurogenic bladder dysfunction due to myelomeningocele: neonatal versus childhood treatment. J Urol 157:2295-2297, 1997

67. Wu HY, Kogan BA, Baskin LS, Edwards MS: Long-term benefits of early neurosurgery for lipomyelomeningocele. J Urol 160:511-514, 1998

Manuscript submitted June 14, 2012.

Accepted July 10, 2012.

Please include this information when citing this paper: DOI: 10.3171/2012.7.FOCUS12232.

Address correspondence to: Chirag D. Gandhi, M.D., Department of Neurological Surgery, New Jersey Medical School, University of Medicine and Dentistry of New Jersey, 90 Bergen Street, Suite 8100, Newark, New Jersey 07101-1709. email: gandhich@umdnj.edu. 